\title{
Belching in Irritable Bowel Syndrome: An Impedance Study
}

\author{
Tuba Obekli, ${ }^{1}$ Filiz Akyuz, ${ }^{2 *}$ Umit Akyuz, ${ }^{3}$ Serpil Arici, ${ }^{2}$ Raim iliaz, ${ }^{2}$ Suut Gokturk, ${ }^{2}$ Sami Evirgen, ${ }^{2}$ Bilger Cavus, ${ }^{2}$ Cetin Karaca, ${ }^{2}$ \\ Kadir Demir, ${ }^{2}$ Fatih Besisik, ${ }^{2}$ and Sabahattin Kaymakoglu ${ }^{2}$ \\ ${ }^{1}$ Department of Internal Medicine, Istanbul Faculty of Medicine, Istanbul University, Istanbul, Turkey; ${ }^{2}$ Division of Gastroenterohepatology, \\ Department of Internal Medicine, Istanbul Faculty of Medicine, Istanbul University, Istanbul, Turkey; and ${ }^{3}$ Department of Gastroenterology, \\ Fatih Sultan Mehmet Educational and Research Center, Istanbul, Turkey
}

\section{Background/Aims}

There are limited data about the relation between belching and irritable bowel syndrome (IBS). We aim to evaluate belching in patients with IBS.

\section{Methods}

Twenty-five patients with IBS and 12 healthy volunteers were enrolled in the study. IBS was diagnosed in accordance with the Rome III criteria. All patients were questioned about the presence of symptoms for belching, gastroesophageal reflux disease, and dyspepsia. Esophageal manometry and 24-hour pH-impedance were performed in all patients and healthy volunteers. Each of the patients with IBS underwent gastroscopy and colonoscopy.

\section{Results}

Demographic features were similar in both groups $(P>0.05)$. The belching rate was $32 \%$ in patients with IBS. The mean DeMeester score was significantly higher in IBS patients (13.80 \pm 14.40 vs $6.04 \pm 5.60, P=0.027)$ and $24 \%$ of patients had pathologic acid reflux (DeMeester score $>14$ ). Gastroscopy was normal in all patients. Symptom association probability positivity was detected in $24 \%$ of patients in the impedance study. The rate of weak acid reflux was also significantly higher in patients with IBS (97.00 \pm 56.20 vs $58.20 \pm 29.30, P=0.025)$. The number of supine gas reflux $(7.50 \pm 6.40$ vs $2.42 \pm 2.80, P=0.001)$ and supragastric belches was significantly higher in patients with IBS $(51.20 \pm 41.20$ vs $25.08 \pm 15.20, P=0.035)$. Although the number of gastric belching was higher in controls, the difference did not reach statistical significance $(12.10 \pm 17.60 \mathrm{vs} 4.90 \pm 3.80, P=0.575)$. We did not find any correlation between belching and any symptoms of IBS.

\section{Conclusions}

Belching is frequent in patients with IBS. Non-erosive reflux disease is frequent in IBS, which may be related to supragastric belching.

(J Neurogastroenterol Motil 2017;23:409-414)

Key Words

Belching; Gastroesophageal reflux; Impedance; Irritable bowel syndrome

Received: June 26, 2016 Revised: September 17, 2016 Accepted: September 25, 2016

(a) This is an Open Access article distributed under the terms of the Creative Commons Attribution Non-Commercial License (http://creativecommons. org/licenses/by-nc/4.0) which permits unrestricted non-commercial use, distribution, and reproduction in any medium, provided the original work is properly cited.

*Correspondence: Filiz Akyuz, MD

Division of Gastroenterohepatology, Department of Internal Medicine, Istanbul Faculty of Medicine, Istanbul University, 34390

Capa, Istanbul, Turkey

Tel: +90-2124142000/31140, Fax: +90-2126319743,E-mail: filizakyuz@hotmail.com 


\section{Introduction}

Irritable bowel syndrome (IBS) is a common functional gastrointestinal disease in routine practice. It does not affect mortality and morbidity although it greatly decreases life quality. ${ }^{1-3}$

In society-based studies, upper gastrointestinal system symptoms such as heartburn, regurgitation, dyspepsia, early satiety, and nausea have been shown to be common in patients with IBS. ${ }^{3,4}$ Although gastroesophageal reflux, dyspepsia, and IBS are considered to be different diseases, it is highly possible that there is some overlap because they have common clinical properties. ${ }^{3}$

Belching may be seen as an isolated symptom. It occurs commonly and can only be considered a functional disorder when it is excessive and becomes troublesome (several times a week) according to the Rome III criteria. ${ }^{3}$ It is a commonly-reported symptom associated with various disorders including gastroesophageal reflux disease (GERD) and functional gastrointestinal system disorders. However, there are limited data about the frequency of belching in IBS. Most of these studies results are symptom or 24-hour $\mathrm{pH}$ metry based. On the other hand, the impedance study which is a newly developed technique can determine the content, direction, localization, and character of the bolus (liquid, gas, and mix) of all reflux episodes and characterize the belching (supragastric or gastric). We aim to evaluate belching in patients with IBS using esophageal 24-hour $\mathrm{pH}$-impedance monitoring.

\section{Materials and Methods}

\section{Study Population}

Twenty-five patients with IBS, which was diagnosed based on the Rome III diagnostic criteria, ${ }^{3}$ and 12 healthy volunteers who presented to the Department of Gastroenterohepatology and Internal Medicine outpatient clinics from January 2013 to March 2014, were enrolled in this prospective study. All patients who participated in the study were informed about the study and signed the Helsinki declaration. The Ethics Committee of Istanbul Faculty of Medicine approved the study.

\section{Study Design}

All patients were questioned about the presence of symptoms for GERD, dyspepsia, and belching. GERD symptoms were considered as heartburn and/or acid regurgitation that occurred at least once per week. Troublesome and excessive repetetive belching (at least several times a week) was accepted as a disorder according to Rome III criteria.

IBS and dyspepsia was diagnosed in accordance with the Rome III criteria. ${ }^{3}$ IBS patients was also classified as diarrhea dominant IBS, constipation dominant IBS, and mixed IBS according to Rome III criteria. ${ }^{3}$ Body mass index was calculated $\left(\mathrm{kg} / \mathrm{m}^{2}\right)$.

Patients who had any operation history, comorbidities, malignancies, and any drug use that may have affected the results (eg, proton pump inhibitor [discontinued at least 2 weeks], acetylsalicylic acid NSAIDs, selective serotonin reuptake inhibitors, and calcium channel blockers) were excluded.

Healthy volunteers had no current or past disease and visited the hospital only for the purpose of a routine examination. These people were questioned about gastrointestinal system symptoms. They had no symptoms of gastroesophageal reflux or the gastrointestinal system. Esophageal manometry and 24-hour esophageal $\mathrm{pH}$-impedance monitoring were performed in all participants.

The site of the lower esophageal sphincter (LES) was identified by manometry (MMS conventional ballooned dried system). Basal lower esophageal sphincter pressures were measured by pull-through technique after overnight fasting. Ten swallows with $5 \mathrm{~mL}$ of water were performed at 30-second intervals. The $\mathrm{pH}$ impedance measurement was done by MMS recorder (Ohmega Impedance-ambulatory pH-meter; MMS, Enschede, Netherlands) with VersaFlex Z-Impedance $\mathrm{pH}$-meter disposable catheters (Alpine bioMed, FountainValley, CA, USA).

The $\mathrm{pH}$-impedance catheters were pushed forward through the nose under topical anesthesia. This catheter was positioned accordingly into the esophagus to record the $\mathrm{pH}$ at $5 \mathrm{~cm}$ and impedance at $3,5,7,9,15$, and $17 \mathrm{~cm}$ proximal to the LES. We removed the catheter after 24 hours. All participants were told to continue their normal daily activities. The $\mathrm{pH}$-impedance data logger recorded both events and posture changes at the same time. At the end of the study, data were uploaded onto a personal computer. The esophageal pH-impedance data was evaluated by one expert in the study group who was blinded to the symptoms of cases. The trace analysis was performed both manually and automatically via the MMS system. A $50 \%$ decrease in impedance with respect to baseline measurements which started $3 \mathrm{~cm}$ above of LES and continued for at least 3 impedance rings above was accepted as gastroesophageal reflux. Acid reflux was defined as a reflux that stayed below $\mathrm{pH} 4$ for at least 4 seconds. Weak acid reflux was defined as a period of at least 4 seconds in which there was at least 1 unit $\mathrm{pH}$ decrease with reflux $\mathrm{pH}$ remaining between 4 and 7 . Alkaline reflux was defined as a reflux with $\mathrm{pH}>7$. 
$\mathrm{pH}$-impedance analysis classified each reflux event as liquid reflux, gas reflux, or mixed reflux of liquid and gas. During the analysis of data, we determined the total number of reflux events (as acid, weakly acid, and alkaline), percent of time spent at $\mathrm{pH}<4$, and the total number of episodes at $\mathrm{pH}<4$ throughout the study (during one day) in the upright and supine positions, and during the night time period. We evaluated also the bolus exposure time, DeMeester score (DMS), and symptom association probability (SAP). SAP positivity was determined as $P<0.05$. The gastric belch is characterized by an increase in impedance $(\geq 1000 \Omega)$ that moves in the oral direction, and supragastric belching is defined as a rapid rise in impedance $(\geq 1000 \Omega$ ) moving in an abnormal direction, followed by a return to baseline moving in the opposite direction according to previously published criteria by Bredenoord et al. ${ }^{5}$ Meal periods were not analyzed. Zerbibet al's studies ${ }^{6}$ in healthy people were taken as normal reference values. Values from the healthy controls and the patient group were compared.

Manometric abnormalities were classified as normal, primary, and secondary motility disorders (scleroderma, etc). A primary motility disorder was categorized as achalasia, distal esophageal spasm (simultaneous contractions [ $\geq 20 \%$ wet swallows], intermittent peristalsis, repetitive contractions [ $\geq 3$ peaks], prolonged duration $[>6$ seconds], and retrograde contractions), hypercontractile esophagus (distal peristaltic amplitude $>180 \mathrm{mmHg}$ and distal peristaltic wave duration $>6$ seconds), and ineffective motility disorders ( $>30 \%$ low amplitude $[30 \mathrm{mmHg}]$ distal contraction, $>$ $30 \%$ of contraction are not transmitted). ${ }^{7}$

\section{Statistical Methods}

Statistical analyses were performed using a personal computer with SPSS software (version 15.0; IBM Corp, Armonk, NY, USA). Differences between groups that were independent between themselves were investigated with non-parametric Mann-Whitney $\mathrm{U}$ and Chi-square test. Correlation analyses were under taken using
Pearson and Spearman correlation tests. Values with a $P$-value lower than 0.05 were accepted as statistically significant.

\section{Results}

Demographic features of the 2 group were similar $(P>0.05)$ (Table 1). According to the Rome III criteria subclassifications of IBS were as follows: $52 \%$ constipation dominant IBS $(\mathrm{n}=13)$, $28 \%$ diarrhea dominant IBS $(\mathrm{n}=7)$, and $20 \%$ mixed IBS $(\mathrm{n}=$ $5)$. Forty-four percent of patients $(n=11)$ had only symptoms of IBS. The others had overlap symptoms (gastroesophageal reflux and dyspepsia). In patients with IBS, regurgitation, heartburn and chest pain rates were $12 \%(n=3), 28 \%(n=7)$, and $12 \%(n=3)$, respectively. Nausea, early satiety, and epigastric fullness rates were $16 \%(\mathrm{n}=4), 28 \%(\mathrm{n}=7)$, and $72 \%(\mathrm{n}=18)$, respectively. Control group had no gastrointestinal symptoms. The repetetive belching rate was $32 \%(n=8)$ in patients with IBS. On the other hand, supragastric belching was also detected by the impedance technique $(52.40 \pm 44.80)$ in other 17 patients who did not mention repetetive belching by questionnaire.

Gastroscopy was normal in all patients with IBS. Esophageal motility was normal in $64 \%$ of patients with IBS; a motility disorder was determined in the remaining $36 \%$ ( 8 ineffective motility and 1 hypercontractile esophagus). Two (16\%) ineffective motility disorders were detected in the control group $(P=0.209)$.

Mean LES pressures of patients and controls were similar $(17.48 \pm 7.02$ vs $16.00 \pm 1.50 \mathrm{mmHg}$, respectively; $P>0.05)$. Hypotensive LES ( $<10 \mathrm{mmHg}$ ) was determined only in 2 (8\%) patients with IBS.

Weak acid or acid reflux was detected in $24(96 \%)$ patients with IBS and weak acid reflux was found in $8(66 \%)$ healthy volunteers $(P=0.030)$ (Table 2).The total number of acid reflux events was higher in IBS patients than in controls $(33.90 \pm 17.20$ vs $19.90 \pm$ $14.40, P=0.002)$. The mean DMS was significantly higher in pa-

Table 1. Demographic Features of 2 Groups

\begin{tabular}{lccc}
\hline & Control $(\mathrm{n}=12)$ & IBS (n=25) & $P$-value \\
\hline Age (mean $\pm \mathrm{SD}, \mathrm{yr})$ & $43.10 \pm 10.60$ & $39.30 \pm 13.10$ & 0.413 \\
Sex (n [\%]) & $7(58.0)$ & $11(44.0)$ & 0.321 \\
Male & $5(41.0)$ & $14(56.0)$ & 0.124 \\
Female & $28.50 \pm 8.90$ & $26.10 \pm 3.90$ & 0.136 \\
BMI (mean $\left.\pm \mathrm{SD}, \mathrm{kg} / \mathrm{m}^{2}\right)$ & $4(33.3)$ & $3(12.0)$ & 0.530 \\
Smoking (n [\%]) & $2(16.7)$ & $3(12.0)$ & \\
Alcohol (n [\%]) & & \\
\hline
\end{tabular}

IBS, irritable bowel syndrome; BMI, body mass index. 
Table 2. Impedance Results

\begin{tabular}{|c|c|c|c|}
\hline Impedance results & Control $(\mathrm{n}=12)$ & $\operatorname{IBS}(\mathrm{n}=25)$ & $P$-value \\
\hline \multicolumn{4}{|l|}{ Impedance results (n [\%]) } \\
\hline Normal & $4(33.3)$ & $1(4.0)$ & \\
\hline Abnormal & $8(66.7)$ & $24(96.0)$ & 0.030 \\
\hline Pathologic acid reflux (n) & 0 & 7 & \\
\hline Weak acid reflux (n) & 8 & 17 & \\
\hline Alkaline reflux (n) & 0 & 0 & \\
\hline $\mathrm{DMS}($ mean $\pm \mathrm{SD})$ & $6.04 \pm 5.60$ & $13.80 \pm 14.40$ & 0.027 \\
\hline $\mathrm{BET}($ mean $\pm \mathrm{SD}, \min )$ & $12.00 \pm 7.70$ & $18.00 \pm 9.20$ & 0.097 \\
\hline Acid reflux number $($ mean $\pm \mathrm{SD})$ & $19.90 \pm 14.40$ & $33.90 \pm 17.20$ & 0.016 \\
\hline Upright & $18.40 \pm 13.70$ & $27.10 \pm 14.80$ & 0.124 \\
\hline Supine & $1.50 \pm 2.10$ & $6.80 \pm 7.50$ & 0.04 \\
\hline $\mathrm{pH}<4$ time $(\%)($ mean $\pm \mathrm{SD})$ & $2.30 \pm 3.00$ & $3.60 \pm 3.40$ & 0.151 \\
\hline Upright & $2.60 \pm 3.20$ & $4.00 \pm 4.80$ & 0.240 \\
\hline Supine & $0.38 \pm 0.77$ & $3.10 \pm 4.30$ & 0.040 \\
\hline Non acid number (mean $\pm \mathrm{SD})$ & $58.20 \pm 29.30$ & $97.00 \pm 56.20$ & 0.025 \\
\hline Upright & $54.40 \pm 28.80$ & $83.00 \pm 54.60$ & 0.102 \\
\hline Supine & $3.80 \pm 4.70$ & $13.80 \pm 9.80$ & 0.001 \\
\hline Alkaline period number $($ mean $\pm \mathrm{SD})$ & $105.50 \pm 117.80$ & $40.60 \pm 47.60$ & 0.410 \\
\hline Gas reflux number (mean $\pm \mathrm{SD})$ & $37.20 \pm 21.50$ & $56.04 \pm 42.20$ & 0.203 \\
\hline Upright & $34.80 \pm 20.30$ & $47.2 \pm 39.90$ & 0.620 \\
\hline Supine & $2.42 \pm 2.80$ & $7.50 \pm 6.40$ & 0.001 \\
\hline Acid gas & $0.92 \pm 1.30$ & $2.10 \pm 3.30$ & 0.160 \\
\hline Non-acid gas & $36.25 \pm 20.90$ & $52.00 \pm 41.10$ & 0.312 \\
\hline Supragastric belching & $25.08 \pm 15.20$ & $51.20 \pm 41.20$ & 0.035 \\
\hline Gastric belching & $12.10 \pm 17.60$ & $4.90 \pm 3.80$ & 0.575 \\
\hline
\end{tabular}

IBS, irritable bowel syndrome; DMS, DeMeester score; BET, bolus exposure time.

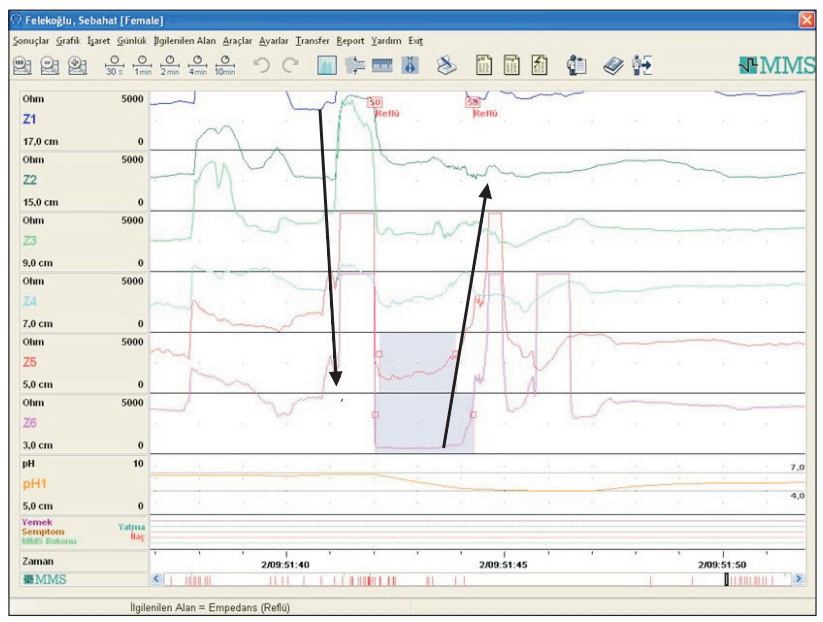

Figure 1. Supragastric belching (arrows show the direction of belching) and weak acid reflux with supragastric belching.

tients with $\operatorname{IBS}(13.8 .0 \pm 14.40$ vs $6.04 \pm 5.60, P=0.027)$, and $24 \%(\mathrm{n}=6)$ had symptoms associated with pathologic acid reflux. Weak acid reflux was determined in 8 patients in the control group,

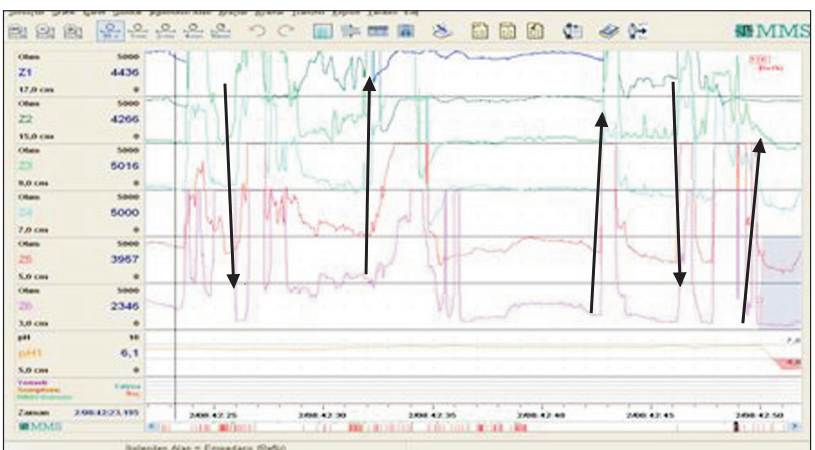

Figure 2. Repetitive belching (arrows show the direction) and acid reflux with the last belching.

none of whom had symptoms.

The rate of weak acid reflux was also significantly higher in patients with IBS (97.00 \pm 56.20 vs $58.20 \pm 29.30, P=0.025)$. The number of supine gas reflux $(7.50 \pm 6.40$ vs $2.42 \pm 2.80, P$ $=0.001$ ) and supragastric belches (Fig. 1 and 2) was significantly higher in the IBS group than in controls $(51.20 \pm 41.20$ vs 25.08 


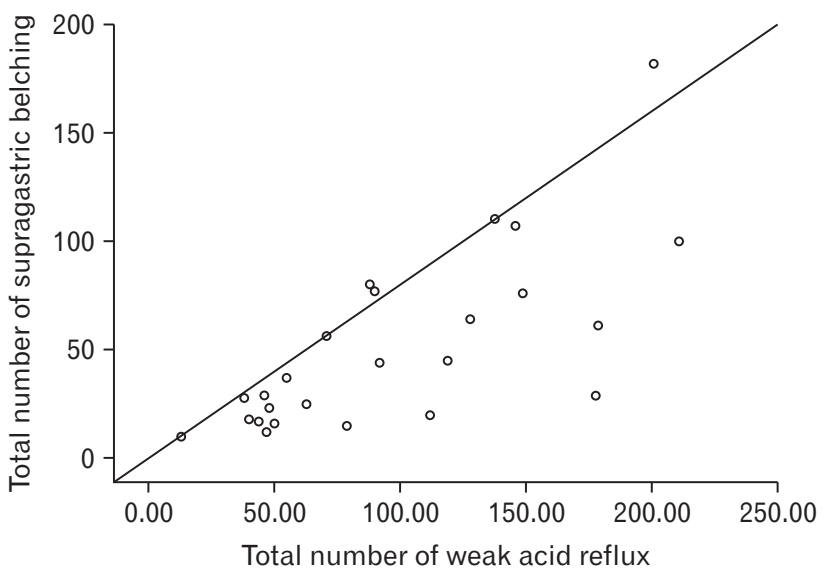

Figure 3. Positive correlation was detected between supragastric belch and total number of weak acid reflux events $(P=0.001, r=0.731)$.

$\pm 15.20, P=0.035)$. However, the number of gastric belches was similar between controls and patients $(12.10 \pm 17.60$ vs $4.90 \pm$ $3.80, P=0.575)$ (Table 2).

A positive correlation was detected between supragastric belching and the total number of weak acid reflux events $(P=0.001, r$ $=0.731)$ (Fig. 3). We found no significant relation between belching and any symptoms of IBS $(P<0.05)$.

\section{Discussion}

Belching is the most common symptom in patients with functional gastrointestinal disorders in routine clinical practice. Although GERD, dyspepsia, and IBS are seen as different diseases, the probability of overlap in these clinical conditions is high because they have common clinical properties and share a similar pathophysiology. ${ }^{8,9}$ Patients with GERD often report an increased frequency of belching. ${ }^{10}$

In this study, we found that repetetive belching is frequent in patients with IBS (32\%). We also evaluated belching in patients with IBS using 24-hour $\mathrm{pH}$-impedance monitoring. However, only one-third of patients who had belching by impedance analyses were symptomatic. Impedance results showed that $24 \%$ of patients with IBS had pathologic acid reflux (DMS $>14$, SAP positivity 24\%). In the literature, GERD prevalance varies from 24.0-63.6\% in IBS. ${ }^{11-13}$ IBS prevalance varies between $24-60 \%$ in GERD. ${ }^{13-14}$ In one study, the authors reported that non-erosive reflux disease was more frequent than erosive esophagitis in patients with IBS. ${ }^{15}$ In our study, gastroscopic examinations were normal in all patients with IBS, which is compatible with the literature.

There are limited studies in the literature that have examined the relationship between GERD and aerophagia/belching. ${ }^{16-18}$ However, some found no relationship between the occurrence of acid reflux and air swallowing, size of the intragastric air bubble, and the number of belches, concluding that belching and acid reflux were not causally related. ${ }^{17}$ Conversely, another study of the same group showed that belches that coincided with liquid reflux events were more often symptomatic than isolated belches. ${ }^{18}$ On the other hand, Koukias et $\mathrm{al}^{19}$ found that pathological acid exposure is associated with more supragastric belching frequency.

To our knowledge, belching has not been evaluated in patients with IBS by impedance. The Rome III criteria distinguishes aerophagia (air swallowing) from unspecified excessive belching. ${ }^{20}$ It was believed that repetitive belching formed after excess amounts of air had been swallowed, it then passed from the stomach to the esophagus and then to the pharynx. However, after the introduction of impedance studies, 2 different belching patterns (supragastric and gastric) were determined. In gastric belching, air passes from the stomach to the esophagus and is discharged from the mouth. However, in supragastric belching, engulfed air can be trapped before passing to the stomach; this is also discharged from the mouth. Bredenoord et $\mathrm{al}^{5}$ showed that supragastric belching lead to repetitive belching.

In our study, supragastric and gastric belching were evaluated in patients with IBS. We found that supragastric belching was more frequent in the IBS group than in controls $(P=0.035)$; however gastric belching was similar in the 2 groups. Bredenoord et $\mathrm{al}^{21}$ reported that psychologic factors have an important role in frequent belching. Psychologic factors are also important in the pathophysiology of IBS. As a result, it was not unexpected to find a higher rate of supragastric belching in patients with IBS than in controls. Regardless, we found no correlation between belching and any symptoms of IBS. However, the SAP positive reflux rate was $24 \%$ in these patients. In addition, the existence of a positive correlation between supragastric belching and the total number of weak acid reflux events $(P<0.001, r=0.731)$ suggest that greater frequency gastroesophageal reflux in patients with IBS may be related with supragastric belching.

As a limitation, only 25 patients with IBS were enrolled in the study. IBS is commonly divided (Rome III criteria) as diarrhea dominant IBS, constipation dominant IBS, and mixed IBS. Approximately half of our patients had constipation dominant IBS (52\%). But, we could not perform a subgroup analysis because of the limited number of patients.

On the other hand, according to our knowledge, this is the first study that evaluated belching in IBS patients using an appropriate 
and modern impedance method.

In conclusion, IBS can be seen as overlapping with GERD. Belching and other functional gastrointestinal symptoms are frequent in patients with IBS. Non-erosive reflux disease is frequent in IBS, which may be related with supragastric belching.

Acknowledgements: Thanks to Mr David Chapman for language editing.

Financial support: This study was invested by Istanbul University and supported by the Rectorate Scientific Research Unit (Project No. 37969).

\section{Conflicts of interest: None.}

Author contributions: Akyuz Filiz, mentor and primary investigator, was responsible for the study concept and design; Obekli Tuba, Akyuz Umit, İliaz Raim, Gokturk Suut, Evirgen Sami, and Cavus Bilger were responsible for data collection and analysis; Karaca Cetin, Demir Kadir, Besisik Fatih, and Sabahattin Kaymakoglu were responsible for critical revision of the manuscript for important intellectual content; and Serpil Arici performed the impedance and manometry.

\section{References}

1. Irvine EJ, Ferrazzi S, Pare P, Thompson WG, Rance L. Health-related quality of life in functional GI disorders: focus on constipation and resource utilization. Am J Gastroenterol 2002;97:1986-1993.

2. Longstreth GF, Wilson A, Knight K, et al. Irritable bowel syndrome, health care use and costs: a U.S. managed care perspective. Am J Gastroenterol 2003;98:600-607.

3. Longstreth GF, Thompson WG, Chey WD, Houghton LA, Mearin F, Spiller RC. Functional bowel disorders. Gastroenterology 2006;130:1480-1491.

4. Lowell RM, Ford AC. Prevalence of gastro-esophageal reflux-type symptoms in individuals with irritable bowel syndrome in the community: a meta-analysis. Am J Gastroenterol 2012;107:1793-1802.

5. Bredenoord AJ, Weusten BL, Sifrim D, Timmer R, Smout AJ. Aerofagia, gastric and supragastric belching: a study using intraluminal electrical impedance monitoring Gut 2004;53:1561-1565.

6. Zerbib F, Roman S, Bruley Des Varannes S, et al. Normal values of pharyngeal and esophageal 24-hour $\mathrm{pH}$ impedance in individuals on and off therapy and interobserver reproducibility. Clin Gastroenterol Hepatol 2013;11:366-372.

7. Lacy BE, Weiser K. Esophageal motility disorders: medical therapy. J Clin Gastroenterol 2008;42:652-658.

8. Lovell RM, Ford AC. Global prevalence of and risk factors for irritable bowel syndrome: a meta-analysis. Clin Gastroenterol Hepato 2012;10:712-721, e4.

9. Yarandi SS, Nasseri-Moghaddam S, Mostajab P, Malekzadeh R. Overlapping gastroesophageal reflux disease and irritable bowel syndrome: increased dysfunctional symptoms. World J Gastroenterol 2010;16:12321238.

10. Klauser AG, Schindlbeck NE, Muller-Lissner SA. Symptoms in gastrooesophageal reflux disease. Lancet 1990;335:205-208.

11. Kennedy TM, Jones RH, Hungin AP, O'flanagan H, Kelly P. Irritable bowel syndrome, gastro-oesophageal reflux, and bronchial hyper-responsiveness in the general population. Gut 1998;43:770-774.

12. Lee SY, Lee KJ, Kim SJ, Cho SW. Prevalence and risk factors for overlaps between gastroesophageal reflux disease, dyspepsia, and irritable bowel syndrome: a population-based study. Digestion 2009;79:196-201.

13. Guillemot F, Ducrotté P, Bueno L. Prevalence of functional gastrointestinal disorders in a population of subjects consulting for gastroesophageal reflux disease in general practice. Gastroenterol Clin Biol 2005;29:243246.

14. Fass R, Stanghellini V, Monnikes H, et al. Baseline analysis of symptom spectrum in GERD clinical trial patients: result from ReQuest (TM) database. Gastroenterology 2006;130:A629.

15. Nam SY, Ryu KH, Park BJ. Irritable bowel syndrome is associated with gastroesophageal reflux symptom but not erosive esophagitis. J Neurogastroenterol Motil 2013;19:521-534.

16. Bredenoord AJ, Weusten BL, Timmer R, Smout AJ. Air swallowing, belching, and reflux in patients with gastroesophageal reflux disease. Am J Gastroenterol 2006;101:1721-1726.

17. Bredenoord AJ, Weusten BL, Timmer R, Akkermans LM, Smout AJ Relationships between air swallowing, intragastric air, belching and gastrooesophageal reflux. Neurogastroenterol Motil 2005;17:341-347.

18. Kessing BF, Bredenoord AJ, Velosa M, Smout AJ. Supragastric belches are the main determinants of troublesome belching symptoms in patients with gastro-oesophageal reflux disease. Aliment Pharmacol Ther 2012; 35:1073-1079

19. Koukias N, Woodland P, Yazaki E, Sifrim D. Supragastric belching: prevalence and association with gastroesophageal reflux disease and esophageal hypomotility. J Neurogastroenterol Motil 2015;21:398-403.

20. Tack J, Talley NJ, Camilleri M, et al. Functional gastroduodenal disorders. Gastroenterology 2006;130:1466-1479.

21. Bredenoord AJ, Weusten BL, Timmer R, Smout AJ. Psychological factors affect the frequency of belching in patients with aerophagia. Am J Gastroenterol 2006;101:2777-2781 